\title{
РОССИЙСКАЯ ИМПЕРИЯ В ПОИСКАХ ОПТИМАЛЬНОЙ МОДЕЛИ УПРАВЛЕНИЯ СЕВЕРОКАВКАЗСКОЙ ОКРАИНОЙ (К ВОПРОСУ ОБ УЧРЕЖДЕНИИ НАМЕСТНИЧЕСТВА)
}

В статье рассказывается о причинах и обстоятельствах учреждения на Кавказе института наместничества. Столкнувшись с сопротивлением немалой части местных обществ распространению имперских порядков, в условиях неблагоприятной внешнеполитической обстановки, власти решили предоставить широкие полномочия своей администрации в регионе. Впервые такая модель была опробована Екатериной II и дала в целом положительный результат. Пользуясь своей широкой автономией, наместник мог оперативно решать важные вопросы, связанные с воздействием на ситуацию на вверенной его попечению территории. Отказ от наместничества осложнил принятие своевременных управленческих усилий по контролю над краем. В немалой степени это было обусловлено субъективными причинами, которые затрудняли предоставление столь широкой автономии какому-либо подданному. Вновь к идее наместничества вернулись в условиях серьёзного военно-политического кризиса, вызванного неудачами в борьбе против теократического государства - имамата Допущенные просчёты наглядно продемонстрировали, что управление Кавказом из Петербурга лишь приводит к новым людским и материальным потерям. Среди кандидатов на должность наместника наиболее оптимально подходил М. С. Воронцов. Он пользовался безусловным доверием императора и обладал необходимыми военными, хозяйственными и административными компетенциями. Восстановленное наместничество доказало свою эффективность и позволило успешно решить те задачи, которые стояли перед империей на Кавказе. Оно продолжало существовать даже после того, как накал вооружённого противостояния в регионе был преодолён, и правительство приступило к мирному обустройству края.

Ключевые слова: наместничество, регион, управление, территория, государство, власть, население, традиция, правление.

\section{THE RUSSIAN EMPIRE IN SEARCH OF OPTIMAL MANAGEMENT MODEL OF THE NORTH-CAUCASUS BORDERLANDS (ON THE FOUNDING OF VICEGERENCY)}

The article studies the reasons and circumstances of founding the institute of vicegerency. Facing the resistance of a part of local communities to spread imperial rules in the conditions of the unfarouble foreign policy, the authorities decided to invest their regional administration with full powers. For the first time the model was tested by Catherine II and gave a positive result . Exercising the autonomy the vicegerent could address the issues promptly and manage the territory in charge. The abandonment of vicegerency complicated the adaptation of timely administrative efforts to control the region. To a certain extent, it was caused by subjective reasons, which made it difficult to delegate such autonomy to some $s$. The idea of vicegerency was addressed againin the conditions of a serious military and political crisis caused by failures in the struggle against the

Столкнувшись с непростыми северокавказскими реалиями, российская власть вынуждена была искать такую модель управления, которая позволила бы эффективно решать здесь многочисленные проблемы в условиях динамично меняющейся ситуации. Автохтонное население региона не имело опыта жизни в составе государства, регламентация отношений здесь происходила на основе традиций и обычаев, которые не theocratic state - imamat. The blunders clearly demonstrated that managing the Caucasus from St. Petersburg only led to new human and material losses. M.S. Vorontsov suited the post of vicegerent more than other candidates did. He enjoyed the unconditional confidence of the emperor and possessed the necessary military, economic and administrative competencies. The restored vicegerency proved its effectiveness and allowed to successfully solve the tasks that the empire faced in the Caucasus. It was preserved even after the heat of the armed confrontation in the region when the government started peaceful development of the region.

Key words: vicegerency, region, management, territory, state, power, population, tradition, government.

всегда могли сосуществовать с правовой основой империи. Достаточно вспомнить такой привычный для местных реалий, но неприемлемый для России вид деятельности, как набеги [9, с. 12]. У исследователей нет общего подхода в оценке данного явления. Его возникновение и развитие связывают с экономической необходимостью, считают институтом социализации и т.п. Но главное заключалось в том, что сохранение подобной 
практики было невозможно в любом виде, а ожидать, что от неё откажутся добровольно, было бы непростительной иллюзией.

У Российского государства имелся достаточно внушительный исторический опыт адаптации иноэтничных территорий в свой состав. Было очевидно, что успех будет зависеть от эффеективности управленческих усилий, которые с одной стороны должны были соотносить свои шаги с Петербургом, а с другой - обладали бы необходимыми полномочиями, чтобы своевременно купировать возникавшие угрозы. И здесь выбор был сделан в пользу наместничества, которое соответствовало выдвигаемым требованиям. Впервые к подготовке этой управленческой модели обратились в 1784 г., когда в руках генерал-губернатора П. С. Потёмкина оказалась власть над огромной территорией, расположенной между Чёрным, Азовским и Каспийским морями. Он мог не только решать вопросы, связанные с обустройством гражданской жизни, но и распоряжаться войсками, сосредоточенными в этих землях. Были созданы условия для колонизации этого порубежья и распространения здесь российской правовой системы. Отметим при этом, что все предпринимаемые шаги соответствовали нормам губернской реформы, проведённой в 1775 г., т.е. осуществлялись в рамках принятых в империи законов.

По велению императрицы Екатерины II 5 мая 1785 г. было учреждено Кавказское наместничество, состоявшее из Кавказской и Астраханской губерний [17, с. 388]. В дальнейшем будут звучать критические замечания о том, что это была слишком большая территория, и эффективно управлять ею невозможно. Но и количество подданных империи здесь было пока невелико, а размеры губернии напрямую зависели от числа проживавших людей. В любом случае, это был процесс поиска наиболее подходящих управленческих форм, который, безусловно, не мог обходиться без ошибок и просчётов.

Назначенный на эту должность П. С. Потёмкин «находился тогда в Петербурге, а потому по возвращении в Георгиевск 30 сентября был принят на Линии уже не только как генерал-губернатор и командир Кавказских корпусов, но как настоящий правитель Кавказа, государев наместник, которому подчинялись все военные и гражданские части» [21, с. 296]. О своевременности таких шагов говорит сама ситуация, с которой пришлось столкнуться наместнику по приезду на Кавказ. Массовые выступления части горских обществ, сплотившихся вокруг религиозного предводителя шейха Мансура, потребовали его экстренного вмешательства чтобы «пресечь самый корень зла» [21, с. 305].

Достаточно энергичные шаги П. С. Потёмкина объяснялись не только его качествами администратора и военачальника, но и теми полномочиями, которые он отныне имел. Представляется возможным говорить о правильности выбранного имперским центром пути на расширение полномочий региональных властей, по крайней мере, когда речь шла о Кавказе. Права у наместника были впечатляющими, но и задачи, которые ставились перед ним, были весьма обширны и касались вопросов, связанных с выстраиванием диалога с местными народами, градостроительством, прокладкой коммуникаций и т.п. [17, с. $388-$ 392]. Каждый раз согласовывать все эти вопросы со столицей было нереально, а потому энергичный руководитель исходил из собственного опыта и интуиции в решении текущих задач.

Жёсткая властная вертикаль, характерная для российской управленческой традиции во многом замыкалась на фигуре первого лица. Пришедший на смену Екатерине II её сын Павел крайне негативно оценивал опыт своей матери. Многие её начинания были отторгнуты, и среди них оказалось Кавказское наместничество. Это был правитель, выступавший за жёсткую властную вертикаль, которая не предусматривала наделения дополнительными полномочиями какого-либо сановника или учреждения. Озвученный 12 декабря 1796 г. данный Сенату именной указ «О новом разделении государства на губернии» временно упразднял в целом полезное начинание и преобразовывал Кавказское наместничество в Астраханскую губернию [18, c. 229-230]. За такими шагами скрывалось не просто желание формально дистанцироваться от достижений предшествующего правления. Здесь присутствовал трезвый расчёт императора, осознававшего невозможность продолжения весьма затратной политики Екатерины II. Это была попытка выстроить диалог с местными народами на новых принципах, в которых политике «ласканий» уделялось гораздо больше внимания, нежели это было прежде [3, с. 30-32].

Последовавшая управленческая путаница показала все недостатки шагов по ликвидации наместничества. Можно было неоднократно наблюдать столкновение интересов двух управленческих структур, которые не столько решали общую задачу, сколько подспудно конкурировали друг с другом. Речь идёт о военном ведомстве и Коллегии иностранных дел. Камнем преткновения стал институт приставства, который нередко действовал, не согласовывая свои решения с представителями армии [2, с. 121]

Ситуация начала меняться с воцарением Александра І. При всех декларируемых либеральных ценностях это был государь, осознававший необходимость сохранения и поддержания принципа единоначалия. Он формально не пошёл на восстановление наместничества, но в 1802 г. соединил военное и гражданское управление Кавказом в одних руках и таким образом ослабил прежние межведомственные склоки. Объединив в одних руках все полномочия, император приказал: «Ныне существующую Астраханскую губернию... разделить на две Астраханскую и Кавказскую. $<\ldots>$ Главный военный и гражданский начальник обеих сих губерний есть инспектор Кавказской Линии и управляющий в Грузии. <..> Гражданские губернаторы или военные, управляющие гражданской частью, состоят в точной его зависимости, но в отсутствии из сих губерний и во время 
пребывания его в Грузии, относятся в Правительствующий сенат и к Министерству по роду дел им подлежащих, прямо от себя, извещая только о том главного начальника» [1, с. 919].

В определённом смысле это была паллиативная мера, т.к. наличие самостоятельных гражданских губернаторов приводило к усложнению схемы принятия решений, плодило бюрократические издержки, тем более что общая ситуация (войны с сопредельными державами, волнения среди горского населения) не позволяла начальнику Астраханской и Кавказской губерний уделять должное внимание всем своим обязанностям В такой ситуации латентное противостояние между гражданскими и военными чинами продолжалось и требовало скорейшего разрешения для общего блага

Шаг в сторону реального единоначалия был сделан после назначения на Кавказ главноуправляющим гражданской частью генерала А. П. Ермолова. Это был энергичный и амбициозный военачальник, к тому же имевший широкие связи в Петербурге [6, с. 10-11]. Он настаивал на предоставлении ему самых широких полномочий которые фактически соответствовали тем правам, какие были у наместника. Примечательно, что в частной переписке он даже называл себя "проконсулом Кавказа», намекая на свои широчайшие возможности в военной и гражданской сорерах. Обращаясь к императору, он испрашивал для себя следующие полномочия: «все части управления в Грузии, Астраханской и кавказской губерниях вверить в непосредственное управление моё и ответственность...», все кадровые вопросы должны были либо решаться самим А. П. Ермоловым либо согласовываться с ним, любые жалобы и недовольство оставлять на рассмотрение самого командира отдельного Грузинского корпуса и т.д. [5, с. 261-264]. Фактически это выводило генерала из-под контроля правительства, что осторожный Александр I допустить не мог. Наделяя А. П. Ермолова значительными полномочиями, он, тем не менее, руками Министерства внутренних дел умерил административные «аппетиты» своего ставленника, чья склонность к фрондёрству была хорошо известна и внушала определённые опасения. Недаром император Николай I поспешил отозвать этого незаурядного государственного деятеля с Кавказа, опасаясь что он может использовать появившуюся у него власть в устранении правящей династии.

Такова была весьма уязвимая сторона такого управленческого решения, как наместничество. Эту должность мог занимать человек, который пользовался абсолютным доверием у первого лица в государстве. В противном случае, имея огромные ресурсы (в том числе боеспособную армию), наместник мог подвергнуться искушению применить их в своих личных целях.

Впрочем, вносить коррективы в управленческую практику Петербург не отказывался. Доказательство тому - «Учреждение для управления Кавказской областью», принятое в 1827 г Этот документ гласил, что: «Кавказская область учреждается в пределах бывшей Кавказской губернии. <...> Главное управление Кавказской области вверяется Главноуправляющему в Грузии. Общий предмет Главноуправляющего есть надзор над правильным и успешным движением всех подчинённых управлений, и доставление им нужных разрешений» [20, с. 108-109].

Отметим тот факт, что управленческий центр Кавказом переносился в Тифрлис. За этим, на первый взгляд, техническим решением скрывалось переосмысление существующих реалий. Проблемы Северного Кавказа, при всей их сложности и затратности, переставали доминировать в тех политических приоритетах, которые были у империи. С точки зрения геополитической значимости, ситуация в полуденных владениях державы явно выходила на первое место и именно ради неё приходилось так выстраивать свой диалог с населением северной части региона, чтобы добиться реального, а не видимого “умиротворения» края. Ставки были слишком высоки, и Россия не могла терпеть ситуации, при которой, вспомним известное высказывание К. Маркса, «...ноги гигантской империи отрезаны от туловища» [15, с. 408].

Bce дальнейшие шаги Николая I были направлены на восстановление наместничества, в разумности которого он убеждался каждый раз, когда Кавказ преподносил ему неприятные «сюрпризы». Пагубность проволочек и не всегда компетентная опека главноуправляющего из Петербурга приводили к осложнению ситуации в крае

Безусловно, мы не утверждаем, что отсутствие упомянутой формы управления стало единственной и главной причиной тех роковых просчётов, которые совершила российская власть в крае, понеся столь кровавые жертвы в борьбе с возникшим религиозным движением мюридизма. Но и игнорировать управленческие просчёты также неприемлемо. В оправдание императора и его советников скажем лишь то, что их внимание отвлекали события как в Польше, так и вокруг неё. Туда приходилось направлять не только дополнительный воинский контингент, но и верных первому лицу людей (И. Ф. Паскевич и И. И. Дибич), которые вполне могли претендовать на пост наместника, т.к. в их личной лояльности новый государь не сомневался.

Между тем в правительственных кругах отсутствовало единство в оценке Кавказа, который мог восприниматься как колония, подобно Индии или Америки, или же как часть империи, пока не способная воспринять привычное гражданское устройство и нуждавшееся в военных методах управления. При разнице в подходах, в обоих случаях мы видим осознание специфики края, его непохожести на прочие части империи. А потому и управление здесь должно было кардинальным образом отличаться в сторону единоначалия и существенной автономности [13, с. 166-167].

Чтобы разобраться с ситуацией на месте Николай I в 1837 г. посещает Кавказ. Со времён Петра Великого подобного «высочайшего ревизора" в регионе не было. Несмотря на желание местных властей «не ударить в грязь лицом», 
увиденное пришлось императору не по нраву. Последовали кадровые перестановки, которые, впрочем, не привели к качественному изменению ситуации. Складывается впечатление, что Николай I посчитал события в крае следствием нерадивости отдельных чиновников, но не смог понять всех глубинных причин происходящих здесь процессов. Как это часто бывает, был назначен виновный (прежде всего, Г. В. Розен), на которого списали военно-политическую напряжённость, хозяйственные неурядицы, финансовые затраты и т.п. Российской политике в регионе явно не хватало системности и постепенности в осуществлении задуманного [7, с. 494].

Возможно, такая неопределённость продолжалась бы и дальше, но активизация «немирных» горцев подтолкнула власти к решительному изменению в управлении краем и возврату к наместничеству [8, с. 95]. И здесь уместно вспомнить обстоятельства, при которых на Кавказе появился М. С. Воронцов. Пожилой граф внезапно оказался наиболее подходящей фигурой, которая могла сыграть роль «кризис-менеджера» в той ситуации, казавшейся тупиковой.

Череда неожиданных военных неудач, потеря контроля над частью горных районов, которые со времён А. П. Ермолова считались надёжно освоенными, - всё это подтолкнуло императора в очередной раз произвести обновление в руководящем составе местной власти. Нужен был человек, известный как опытный администратор и одновременно разбирающийся в военных вопросах. Непременным условием была абсолютная верность императору и умение находить язык с невероятно честолюбивым и амбициозным окружением Николая I.

Всем этим требованиям отвечал М. C. Воронцов, ветеран наполеоновских войн, успешно действующий на хозяйственном поприще в Крыму, человек, умевший ладить с представителями высших сановных кругов империи и, наконец, не нуждавшийся в деньгах, а потому не смотревший на свою должность как на инструмент обеспечения материального благополучия. Граф (позднее князь) был опытным хозяйственником и был сторонником идеи о том, что успешное занятие земледелием, ремеслом и торговлей сделают горцев мирными подданными империи. В последующем и другие кавказские наместники придерживались подобного подхода [11, с. 201].

Хотя идея восстановления наместничества давно витала в воздухе, М. С. Воронцов ехал на Кавказ с грузом многочисленных установок и пожеланий, высказанных ему лично государем. По крайней мере, по-другому сложно объяснить тот факт, что, не успев ознакомиться лично с ситуацией в крае, он заторопился в авантюрную по своей сути Даргинскую экспедицию. Идея генерального сражения принадлежала Николаю І. Именно этого он требовал от своих подчинённых, возможно, уповая на повторение успеха под Ахульго, когда удалось загнать в ловушку многоопытного имама Шамиля, и был шанс покончить с этим давним противником.
Но из виду упускалось то, что даже сотворивший эту победу генерал П. Х. Граббе в дальнейшем потерпел неудачу, пытаясь пройти в Горную Чечню. Шамиль сделал правильные выводы из своего поражения и отныне не давал загнать себя в ловушку. Ни о каком генеральном сражении речь теперь идти не могла, а заняв любой горский аул, армия ни на шаг не приближала себя к победе над неприятелем. Горцы отныне предпочитали действовать на коммуникациях, уловив самую уязвимую сторону российской военной машины. В этом пришлось убедиться и М. С. Воронцову, который, выполняя императорское повеление, взял Дарго и с огромными потерями сумел выйти из окружения, которое организовали для него мюриды.

Для людей, знающих ситуацию, было очевидно, что этот поход, чуть было не обернувшийся катастрофой, личная ошибка Николая І. Но он не услышал от графа, вскоре ставшего князем, ни слова упрёка. Такая позиция была оценена по достоинству, и М. С. Воронцов получил картбланш в своих начинаниях: «Граф Михаил Семёнович! Возложив на вас, вместе с званием Главнокомандующего войсками на Кавказе, и главное начальство над гражданскою частию в том крае, в качестве моего Наместника, находя нужным для пользы службы усилить права, которые доныне были даны Главноуправляющим гражданскою там частию и в полном доверии к лицу вашему... », - говорилось в императорском указе от 30 января 1845 г. и далее следовала целая череда прав и полномочий, которые он получал [19. c. 152]. Наместничество было восстановлено.

Для народов края именно М. С. Воронцов становился олицетворением государства. Племенам, привыкшим к традиционной организации жизни, базирующейся на персонификации власти в лице конкретного человека, а не абстрактного института, это было понятно и близко. Недаром и сам князь подчёркивал, что ни один свод законов не в состоянии заменить воли и рассудка у чиновника, наделённого властью государя [16, с. 95]

В дальнейшем полномочия наместника будут ещё больше расширены. Так, при А. И. Барятинском «происходит значительное усиление военного и гражданского административного аппарата. В 1856 г. Отдельный кавказский корпус был преобразован в Кавказскую армию с большим аппаратом (Главный штаб во главе с начальником и ряд управлений). В 1859 г. канцелярия наместника преобразуется в Главное управление наместника, состоявшее из пяти своеобразных «министерств», называемых «департаментами»: общих дел (заведовало личным составом чиновников, почтами, строительными, медицинскими и учебными делами), судебный, финансовый, государственных имуществ, контрольный. При наместнике существовала даже особая дипломатическая канцелярия» [4, с. 197].

При всей автономности наместничества, оно лишь на первый взгляд становилось государством в государстве. За его работой наблюдал специально созданный орган - Кавказский коми- 
тет. Он не мог ставить препоны М. С. Воронцову но имел возможность советовать ему по разным вопросам, что было вполне разумно, т.к. взгляд со стороны позволял увидеть некие нюансы, не замеченные под грузом текущих дел непосредственно на месте. Согласованию подлежали преимущественно дела, связанные с хозяйственной деятельностью. Предположения наместника могли быть отправлены в профильное министерство а в особых случаях пойти сразу на стол императору. Судьба Кавказского комитета в итоге решится тогда же, когда и примут решение о ликвидации наместничества. Этот орган надзора будет распущен в 1882 г. [4, с. 161].

Последовавшие вслед за расширением полномочий шаги наместника по стабилизации ситуации в крае подтвердили верность выбранного пути. Уже не оглядываясь на указания столичных стратегов, М. С. Воронцов повёл свои дела так, как ему подсказывали его интуиция, немалый управленческий опыт и разумные советы людей которые знали о Кавказе не понаслышке [12 с. 142-149]. И это были не только успешные (отметим при этом - неспешные!) военные операции, но и достаточно разумные шаги по экономическому преображению края. Даже для тех, кто ранее не видел альтернативы набегу и «молодчеству», становилась очевидна вся выгода мирного и созидательного труда [14, с. 228-233]. Не только штык и пуля, но и русская монета исподволь подтачивала фундамент теократической крепости, создаваемой Шамилём и его окружением

Внешнеполитические обстоятельства, политическая ситуация в регионе, социально-экономические процессы, происходившие на остальной части империи и завершившееся вооруженное противостояние с «непримиримой» частью горцев открыли возможности наместничества акцентировать внимание на экономическом освоении края [10, с. 23].
Просуществовав в таком виде до начала 80-х гг. XIX в., наместничество выполнило свою историческую миссию, став переходной формой управления, способной мобилизовать все административные резервы для решения важных и нетерпящих отлагательства вопросов. Когда социальные катаклизмы первой русской буржуазно-демократической революции вновь заставили обратить пристальное внимание на положение в полиэтничном регионе, полученный опыт был вновь востребован государством, и восстановленное наместничество сумело на короткий срок стабилизировать ситуацию в крае.

Поиск оптимальной модели управления Кавказом был делом не одномоментным и противоречивым. Центральной власти оказалось непросто решиться на предоставление столь обширных прав отдельному региону и отдельному подданному. Лишь экстраординарная ситуация заставила впервые пойти на такой эксперимент. Екатерина II, умевшая подбирать незаурядные управленческие кадры в своём окружении, впервые опробовала институт наместничества, соединив военные и гражданские полномочия в руках одного человека. В дальнейшем от такого решения отказались и вернулись к нему лишь в условиях глубочайшего кризиса, в котором оказалась имперская власть на Кавказе. Видимо, здесь сыграл свою роль субъективный фактор, долгое время заставлявший настороженно относиться к любым попыткам упустить из под контроля первого лица часть властных полномочий. Если вспомнить многочисленные заговоры против монарха, такие опасения видятся вполне естественными и мотивированными. Но когда была найдена достойная кандидатура, наместничество сделалось важным и эффективным инструментом обустройства этой части страны.

\section{Источники и литература}

1. Акты, собранные Кавказской археографической комиссией / под ред. А. П. Берже. Т. ІІ. Тифлис: Тип. Главного Управления Наместника Кавказского, 1868. 1238 с.

2. Блиева 3. М. Российский бюрократический аппарат и народы Центрального Кавказа в конце XVIII - 80-е гr. XIX века: дисс. ... док. ист. наук. Владикавказ: СОГУ, 2004. 476 с.

3. Виноградов Б. В. Кавказ в политике государя Павла I 1796-1801 гг.) / под редакцией профессора В. Н. Ратушняка. Армавир - Славянск-на-Кубани: АГПИ, 1999. 115 с.

4. Ерошкин Н.П.История государственных учреждений дореволюционной России. М.: Высшая школа, 1968. 368 c.

5. Кавказ и Российская империя: проекты, идеи, иллюзии и реальность. Начало XIX - начало XX вв. СПб.: Издательство журнала «Звезда», 2005. 720 с.

6. Клычников Ю. Ю. Деятельность А. П. Ермолова на Северном Кавказе (1816-1827) / под ред. и с предисловием В. Б. Виноградова. Ессентуки, 1999. 135 с.

7. Клычников Ю. Ю. Российская политика на Северном Кавказе (1827-1840 гг.) / под ред. В. Б. Виноградова. Пятигорск: ПГЛУ, 2002. 494 с.

8. Клычников Ю. Ю. Российская государственность и северокавказская архаика: В поисках преодоления противоречий (XVIII - начало XXI вв.). Исторические очерки. М.: ЛЕНАНД, 2015. 368 с.

9. Клычников Ю. Ю. Северный Кавказ: старые проблемы в новом измерении (историко-политологические очерки) / под ред. и с предисловием С. Л. Дударева. Пятигорск: ПГЛУ, 2016. 99 с.

10. Гранкин Ю. Ю. Колонизационное освоение Северного Кавказа в пореформенный период // Известия Российского государственного педагогического университета им. А. И. Герцена. 2011. №132. С. 22-33.

11. Гранкин Ю. Ю. Северный Кавказ в 1844-1881 гг.: наместничество и экономические аспекты российской политики в регионе // Былые годы. Российский исторический журнал. 2018. №47 (1). С. 199-207.

12. Клычников Ю. Ю., Лазарян С. С. Мозаика северокавказской жизни: события и процессы XIX - начала XX веков (Исторические очерки). Пятигорск: ПГЛУ, 2012. 330 с. 
13. Лазарян С. С. Военно-политическая и административно-правовая деятельность князя М. С. Воронцова в Кавказском крае. 1845-1854 гг. Пятигорск: ПГЛУ, 2012. 323 с.

14. Лазарян С. С. Очерки и характеристики событий кавказской старины первой половины XIX века / под ред. Ю. Ю. Клычникова. Пятигорск: ПГУ, 2018. 247 с.

15. Маркс К., Энгельс Ф. Сочинения. Издание 2. Т.ІХ. М.: Государственное издательство политической литературы, 1957. $702 \mathrm{c}$.

16. Огарков В. В. Воронцовы и их жизнь и общественная деятельность. Биографические очерки. СПб.: Типография товарищества «Общественная польза», 1892. 96 с.

17. Полное собрание законов Российской Империи. Собрание Первое (ПСЗ-I). Том XXII. СПб.: Тип. II Отделения Собственной Его Императорского Величества Канцелярии, 1830. T.XXII. 1183 с

18. ПСЗ-І. Т.XXIV. СПб.: Тип. II Отделения Собственной Его Императорского Величества Канцелярии, 1830.871 с.

19. Полное собрание законов Российской Империи. Собрание Второе (ПСЗ-ІІ). СПб.: Тип. ІІ Отделения Собственной Его Императорского Величества Канцелярии, 1830. Т.ІІ. Отделение І. 1043 с.

20. ПСЗ-ІІ. СПб.: Тип. ІІ Отделения Собственной Его Императорского Величества Канцелярии, 1830. Т.ІІ. Отделение II. $1560 \mathrm{c}$.

21. Потто В. А. Два века терского казачества (1577-1801) / Репринтное издание. Ставрополь: Кавказская библиотека, $1991.383 \mathrm{c}$.

\section{References}

1. Akty, sobrannye Kavkazskoj arheograficheskoj komissiej (Acts Collected by the Caucasian Archaeological Committee) / ed. by A.P. Berzhe. Vol.II. Tiflis, 1868. 1238 p. (In Russian).

2. Blieva Z. M. Rossijskij byurokraticheskij apparat i narody Central'nogo Kavkaza v konce XVIII - 80-e gg. XIX veka (The Russian Bureaucratic Machinery and Peoples of the Central Caucasus in the End of the XVIII - 80-s XIX century). Vladikavkaz, 2004. 476 p. (In Russian).

3. Vinogradov B. V. Kavkaz v politike gosudarya Pavla I 1796-1801 gg.) (The Caucasus in the Politics of the Sovereign Paul I (1796-1801) / ed. by V. N. Ratushnyak. Armavir - Slavyansk-on-Kuban, 1999. 115 p. (In Russian)

4. Eroshkin N. P. Istoriya gosudarstvennyh uchrezhdenij dorevolyucionnoj Rossii (The History of State Organizations of the Pre-revolutionary Russia). Moscow: Vysshaya shkola, 1968. 368 p. (In Russian).

5. Kavkaz i Rossijskaya imperiya: proekty, idei, illyuzii i real'nost'. Nachalo XIX - nachalo XIX vv. (The Caucasus and Russian Empire: Projects, Ideas, I/lusions and Reality). St.Petersburg: Zvezda, 2005. 720 p. (In Russian).

6. Klychnikov Yu. Yu. Deyatel'nost' A. P. Ermolova na Severnom Kavkaze (1816-1827) (The Activities of A.P. Ermolov in the Northern Caucasus (1816-1827) / ed by V. B. Vinogradov. Essentuki, 1999. 135 p. (In Russian).

7. Klychnikov Yu. Yu. Rossijskaya politika na Severnom Kavkaze (1827-1840 gg.) (Russian Policy in the North Caucasus (1827-1840) / ed by V.B. Vinogradov. Pyatigorsk: PSLU publ., 2002. 494 p. (In Russian).

8. Klychnikov Yu. Yu. Rossijskaya gosudarstvennost' i severokavkazskaya arhaika: $V$ poiskah preodoleniya protivorechij (XVIII - nachalo XXI vV.). Istoricheskie ocherki (The Russian Statehood and North Caucasus Archaic: in Search of Overcoming Contradictions (XVIII - the Beginning of the XIX c.) Historical essays). Moscow: LENAND, 2015. 368 p. (In Russian).

9. Klychnikov Yu. Yu. Severnyj Kavkaz: starye problemy v novom izmerenii (istoriko-politologicheskie ocherki) (The North Caucasus: old problems in the new measuring (historical and politological essays) / ed by S. L. Dudarev. Pyatigorsk: PSLU publ., 2016. 99 p. (In Russian).

10. Grankin Yu. Yu. Kolonizacionnoe osvoenie Severnogo Kavkaza v poreformennyj period (The Colonization of the North Caucasus During the Post-reform Period) // Izvestia: Herzen University Journal of Humanities Science. 2011. No. 132. P. 2233. (In Russian).

11. Grankin Yu. Yu. Severnyj Kavkaz v 1844-1881 gg.: namestnichestvo i ehkonomicheskie aspekty rossijskoj politiki v regione (The North Caucasus in 1844-1881: Economic Aspects of Russian Politics in the Region) // Bylye Gody. Russian Historial Journal. 2018. 47 (1). P. 199-207. (In English).

11. Klychnikov Yu. Yu., Lazaryan S. S. Mozaika severokavkazskoj zhizni: sobytiya i processy XIX - nachala XX vekov (Istoricheskie ocherki) (The Mosaic of Life in the North Caucasus: Events and Processes. XIX - the Beginning of the XX $c$. Historical Essays). Pyatigorsk: PSLU publ., 2012. 330 s. (in Russian).

12. Lazaryan S. S. Voenno-politicheskaya i administrativno-pravovaya deyatel'nost' knyazya M. S. Voroncova $v$ Kavkazskom krae. 1845-1854 gg. (Military, Political, Administrative and Judicial Activities of Prince M.S. Vorontsov in the Caucasus Region). Pyatigorsk: PSLU publ., 2012. 323 p. (in Russian).

13. Lazaryan S. S. Ocherki i harakteristiki sobytij kavkazskoj stariny pervoj poloviny XIX veka (Essays and Characteristics of Events in the Caucasus in Old Times of the First Half XIX Century) / ed by Yu. Yu. Klychnikova. Pyatigorsk: PSU publ. 2018. 247 p. (In Russian).

14. Marx K., Engels F. Sochineniya (Compositions). Vol. IX. Moscow: Gosudarstvennoe izdatel'stvo politicheskoj literatury 1957. 702 p. (In Russian).

15. Ogarkov V. V. Voroncovy i ih zhizn' i obshchestvennaya deyatel'nost'. Biograficheskie ocherki (The Vorontsovs, Their Life and Social Activities. Biographical essays). St. Petersburg, 1892. 96 p. (In Russian).

16. Polnoe sobranie zakonov Rossijskoj Imperii. Sobranie Pervoe (PSZ-I) (The Complete Collection of Laws of the Russian Empire. Collection 1). Vol XXII. St. Petersburg, 1830. 1183 p. (In Russian).

17. PSZ-I. Vol. XXIV. St. Petersburg, 1830. 871 p. (In Russian).

18. Polnoe sobranie zakonov Rossijskoj Imperii. Sobranie Vtoroe (PSZ-II) (The Complete Collection of Laws of the Russian Empire. Collection 2). Vol. II. St. Petersburg, 1830. 1043 p. (In Russian).

19. PSZ-II. St. Petersburg, 1830. Vol. II. 1560 p. (In Russian).

20. Potto V. A. Dva veka terskogo kazachestva (1577-1801) (Two Century of the Terek Cossacks). Reprintnoe izdanie. Stavropol': Kavkazskaya biblioteka, 1991. 383 p. (In Russian). 